\title{
Prescribing patterns of non-steroidal anti-inflammatory drugs (NSAIDs) at outpatient departments of four hospitals.
}

\author{
Mohammed A Alshakka1, Wafa F Badullah², Sultan O Alolayan ${ }^{3}$, Mansour A. Mahmoud ${ }^{\text {* }}$ \\ ${ }^{1}$ Section of Clinical Pharmacy, Aden University, Aden, Yemen \\ ${ }^{2}$ Department of Analytical Chemistry, Aden University, Aden, Yemen \\ ${ }^{3}$ Clinical and Hospital Pharmacy Department, College of Pharmacy, Taibah University, Al-Madinah Al-Munawara, \\ Saudi Arabia
}

\begin{abstract}
Objective: The purpose of the current study was to assess non-steroidal anti-inflammatory drug (NSAIDs) prescription patterns at outpatient departments (OPDs) of four hospitals in Aden-Yemen.

Method: This hospitals-based, cross-sectional descriptive study was conducted from May 2018 through August 2018. WHO drug use indictors were selected to evaluate prescription patterns. Data was collected from patient case files at OPDs.

Results: Prescriptions of 600 patients containing at least one NSAID were nominated for analysis. More than half $(52 \%)$ of prescriptions were prescribed for females and $48 \%$ for males. NSAIDs were prescribed less commonly for patients over $60 \mathrm{y}$ of age $(6 \%)$. The most common indications for NSAIDs were infective conditions $(29.3 \%)$, fever $(9.3 \%)$ and orthopedic pain $(\mathbf{8 . 1 \%})$. The average number of drugs per prescription was 3.5 drugs. Additionally, $18.5 \%$ of the prescriptions contained medicines prescribed by generic name while 73.3\% were from Essential Medicine List (EML). Diclofenac sodium was the most commonly prescribed NSAID (26.6). The average cost of NSAIDs per prescription was 970 Yemeni Riyals (YR).

Conclusion: The prescribing pattern of NSAIDs in Aden city hospitals showed deviation from the standard values of WHO requirements. The result suggests irrational/inappropriate prescribing of NSAIDs, low practice of international nonproprietary names (generic names) in prescriptions and high rate of NSAIDs prescription. In addition, some informational shortage was notable among prescribers concerning prescribing rules.
\end{abstract}

Keywords: NSAIDs, Prescription, Standard therapeutic guidelines, Outpatient departments of hospital, Essential medical list, Aden, Yemen.

\section{Introduction}

The World Health Organization (WHO) defined rational drug prescribing as patients receiving "medications appropriate to their clinical needs, in doses that meet their own individual requirements for an adequate period of time, and the lowest cost to them and their community." [1]. Globally, irrational drug prescribing is a great challenge for health care systems [2] and a widespread phenomenon in developing countries [3]. Some irresponsible practices such as: poly-pharmacy, irrational prescribing of medicines, abuse of injectable medicine and non-compliance to prescribing strategies are the most common [4].

Non-steroidal anti-inflammatory drugs (NSAIDs) are considered among the most every day used medicine all over the world $[5,6]$. NSAIDs are prescribed irrationally in the outpatient department (OPDs). NSAIDs are associated with side effects that range from mild to severe and sometimes fatal $[7,8]$. Nevertheless, there is a need for recurrent assessment of medicinal prescribing manner in order to provide appropriate adjustment in prescription of medicine to enhance curative benefits and reduce the side-effects [9].

Unfortunately, data on prescribing pattern outpatient and inpatients settings in Yemen is limited for all medicine in general and for NSAIDs in particular. Therefore, the main objective of this study was to evaluate prescribing patterns according to the stipulated World Health Organization (WHO) indictors in four hospitals in Aden. The study also aims to provide recommendations for intervention that may be designed to improve prescribing practice. This study will help to recognize the trends in prescribing NSAIDs, and offer strategies for designing proper future intervention policies in 
order to encourage rational prescribing and improve the quality of health care.

\section{Methods}

\section{Study setting and period}

The study was carried out at an Out Patient Department (OPDs) of four selected hospitals in Aden city namely, AlGamhouria Teaching based Hospital, Alsadaqa hospital, Alwali hospital and Yemen-Germany private hospital. These hospitals considered as main referral medical center in Aden city.

\section{Study design}

A cross-sectional descriptive study was conducted in four hospitals in different areas of Aden city, the commercial capital of Yemen. The three purposes behind exploring the use of medicine are; to define the existing manner of medicine use, to amend particular medicine utilization issues, and to observe the quality of medicine use over a period of time. Examination of utilization of medicines in a particular situation can be performed through various actions. This includes surveying current manner of drug utilization; characterizing guidelines of suitable practice and distinguishing the particular problem.

Seven prescription utilization indicators, three centers, one patient, and three complimentary indicators from the WHO drug use indicators (Outpatient facilities) list were evaluated.

\section{Core indicators:}

- Average number of medicines per encounter

- Percentage of medicines prescribed by generic name

- Percentage of medicines prescribed from the EML or formulary

\section{Patient indicator:}

- Percentage of medicines actually dispensed

\section{Complimentary indicators:}

- Average medicine cost per encounter

- Average medicine cost spent on NSAIDs per encounter

- Percentage of prescriptions in accordance with treatment guidelines.

\section{Sampling}

Sample selection was suitable by focusing on four main hospitals. The four hospitals represent government and private hospital practice in Aden city.

\section{Data collection}

Patients' information was collected from their medical files when they presented to the pharmacy department to collect their medications. Information about their present medical conditions and prescribed NSAIDs were recorded in data collection sheets. The prescribed NSAIDs was evaluated for suitability and whether they had been prescribed according to the Standard Treatment Guidelines (STGs). The accessibility of STGs in the OPDs and the rate of referring and adherence to these guidelines by the prescribing doctors were also evaluated.

\section{Data analysis}

The collected data from the respondents were analysed using SPSS $^{\circledR}$ version 21.0. The data from the data collection sheet were evaluated for various parameters. Descriptive statistics such as frequencies, percentages and means were used in the analysis of the data.

\section{Ethical consideration}

The study protocol was approved by the Ethics Research Committee of the Faculty of Medicine and Health Sciences, Aden University. A verbal agreement was attained from all participants who agreed to participate in the study after explaining the objectives, importance and benefits of the research and that the participation is voluntary. Participants were informed that all collected data will be handled with full confidentiality and will be used only for the research purposes.

\section{Results}

Six hundred patients were involved in this study. Prescriptions containing at least one NSAID were included in the analysis. The majority of NSAIDs users were in the age group 12 to 30 $\mathrm{y}$ old $(48.3 \%)$ and $52 \%$ of them were females (Table 1 ). Patients over 60 y old were prescribed NSAIDs less frequently $(6 \%)$.

Infective conditions were the most common clinical conditions in hospitals for which NSAIDs were prescribed in high percentage $(29.3 \%)$ followed by fever $(9.3 \%)$ orthopedic pain (8.1\%) and musculo-skeletal pain (7.8\%) (Table 2).

The most commonly used non-selective COX inhibitor was diclofenac sodium $(26.6 \%)$ followed by meloxicam $(12.8 \%)$ and ibuprofen $(12 \%)$. In addition, combination of two nonselective anti-inflammatory drugs was also presented in this study. The selective COX inhibitor was also used but the frequency was very low. Only $18.5 \%$ of prescribed medicines were mentioned using generic name and $73.3 \%$ of them were form the National Drug List (NDL). The average cost of NSAIDs per prescription was 970 YR. The average number of drugs per prescription was 3.5 .

Table 1. Demographic characteristics of patients taking NSAIDs.

\begin{tabular}{llll}
\hline Demographic factors & Categories & N & $\%$ \\
\hline Age in years & Below 12 y of age & 53 & 8.9 \\
\cline { 2 - 4 } & $12-30$ y & 290 & 48.3 \\
\cline { 2 - 4 } & $30-60$ y & 221 & 36.8 \\
\cline { 2 - 4 } & More than 60 y & 36 & 6 \\
\hline Gender & Male & 288 & 48 \\
\hline
\end{tabular}




Female $\quad 312 \quad 52$

Table 2. Clinical indications.

\begin{tabular}{lll}
\hline Clinical indications & Frequency & Percent \\
\hline Infective condition & 177 & 29.3 \\
\hline Fever & 56 & 9.3 \\
\hline Orthopedic pain & 49 & 8.1 \\
\hline Musculo-skeletal pain & 47 & 7.8 \\
\hline Rheumatoid arthritis & 30 & 5 \\
\hline Osteoarthritis & 24 & 4 \\
\hline Backache & 23 & 3.8 \\
\hline Headache & 17 & 2.8 \\
\hline Traumatic injury & 13 & 2.2 \\
\hline Others & 167 & 27.7 \\
\hline
\end{tabular}

"Total number of NSAIDs=603

\section{Discussion}

The evaluation of drugs prescribing patterns is considered essential to improve clinical and economical outcomes [10]. The main objective of this type of studies is providing findings to the prescribers and to create consciousness about the proper use of drugs [11].

The current study was completed with a specific aim to review a sum of 600 prescriptions containing NSAIDs gathered from the OPDs of four hospitals in Aden. The main aim was to assess the prescribing pattern of NSAIDs, in addition, other WHO specific indictors were studied such as; the pharmacological sub-classes of NSAIDs prescribed, the clinical indications for prescribing NSAIDs and costs of total drugs and of NSAIDs per prescription and an assessment of prescriptions containing NSAIDs with respect to use of generic or trade name. To the best of the authors knowledge the present study is the first of its kind in Yemen to investigate the prescribing pattern of NSAIDs in four hospitals in Aden.

The most encountered clinical indication of using NSAIDs was for infective conditions and fever. In addition, other medical symptoms such as; Orthopedic pain, musculo-skeletal pain, rheumatoid arthritis, osteoarthritis, backache, headache, traumatic injury. Similarly, lower back pain was the most common clinical indication of using NSAIDs in the Orthopedics OPDs in Ajman and Nepal [12,13]. Pain was a common symptom of all patients complains.

Diclofenac sodium was the most commonly prescribed NSAIDs for about $21.5 \%$ of the patients. Comparable rate was reported by a study from Ajman, United Arab Emirates (UAE) [12], while a study from Nepal reported predominantly reported prescription of Meloxicam [13], whereas ibuprofen and piroxicam were found common by another study from Nepal [14]. These results are comparable to Fosbol et al. study, which concluded that ibuprofen and diclofenac were the most frequently used conventional NSAIDs [15]. While IMS Health reported that diclofenac was more common prescribed in the UK. However, in the USA, ibuprofen and naxproxen are the most commonly prescribed NSAIDs [16].In addition, the study revealed that diclofenac sodium injection was used irrationally which could lead to harmful adverse drug reactions such as renal and cardiovascular reactions. Selective COX-2 inhibitors were reported to have lower renal and gastrointestinal complications compared to classical NSAIDs, however, the use of this new class is associated with myocardial infarction and cardio vascular system toxicity [17-21]. In the current study, the percentage of using selective COX-2 inhibitors is considered low in comparison to the classical NSAIDs (3.5\%), this may be due to high price of selective COX-2 inhibitors in contrast to the conventional NSAIDs and financial difficulties faced by some patients [22,23]. The result was closely comparable to a study conducted in Jordan with only $3.5 \%$ and another study of about $4 \%$ for using selective COX-2 inhibitors with a different survey period $[24,25]$. In contrast, other studies showed higher levels of prescribing selective COX-2 inhibitors $[26,27]$. The conventional and the selective NSAIDs are broadly prescribed for indications including osteoarthritis, rheumatoid arthritis, and acute pain. However, both classes of drugs have identical clinical efficacy [28-30].

The number of drugs prescribed by generic name in the present study was $18.5 \%$. This finding is considered too low according to the WHO standard for the developing countries which is $100 \%$ [31] and relatively similar to the other studies that ranged from $3 \%$ to $20 \%$. [32-35]. Nevertheless, it is low in comparison to other studies in other developing country like Nigeria (49.5-58\%) [36-38]. Relatively close to the ideal percentages of WHO standard were reported by studies from other developing countries like; Tanzania (94\%) [39], Eastern and Southern Ethiopia (97-98.7\%) [40,41] and Bengal (98.5\%) [42]. Although, a study in Ajman, UAE revealed that none of the medicines were prescribed by generic name [12] which is also similar to that reported by a study in eastern Nepal [14]. The practice of prescribing drugs by generic name is essential in order to increase the rational use of drugs, reduce dispensing errors and cost per prescription. Around $73.3 \%$ of prescribed drugs was from the EML, which is lower than the value recommended by WHO 100\% [43].

The higher cost of drugs per prescription is related to the use of trade name instead of generic names and poly-pharmacy. The result of drug cost was $4700 \mathrm{YR}$ per prescription and about 970 YR for NSAIDs, which is considered expensive for the majority of patients due to the low level of individual income in Yemen in comparison to other developing countries. Isenalumhe specified that the cost of drugs per prescription can be an indication of patient non-adherence to medication [44]. Commitment of using generic names may result in reducing the cost of prescriptions.

The mean number of drugs per prescription is an important guide for the evaluation of the prescribing patterns of the physician and recognizing the weakness points in order to 
provide appropriate intervention. The mean number of medicines per prescription in the present study was 3.5 which is considered high according to the recommended WHO standard (1.6-1.8) [43]. The reported result in the current study regarding number of drugs per prescription is higher than a study carried out in eastern and southern Ethiopia (2.2-1.9) [40,41]. Also, other studies indicated a lower number of drugs per prescription $(2.5,1.9,1.3)[13,14,45]$. Results that are similar to our study were reported in Ajman, United Arab Emirates [12]. The finding from this study indicates that polypharmacy prescribing is common among physicians in Yemen.

The main limitation of the study is that the results were obtained from health care professionals working only in one city in Yemen. However, it is estimated that prescribing practice is similar all over Yemen. Therefore the results may be representative.

\section{Conclusion}

It can be concluded form this study that prescribing patterns in Aden, Yemen has several limitations in relation to the WHO indicators. There is a need to review drug utilization practice and physicians compliance with EML. Policy makers such as the Ministry of Health should enforce sanction on physicians who do not comply with standards and procedures. Generic drug prescribing should be encouraged by the policy makers.

\section{References}

1. World Health Organization. The rational use of drugs. report of the conference of experts. Geneva. WHO 1985.

2. Report of a conference of experts, Nairobi, November 24-29, 1985. The rational use of drugs. WHO Geneva 1987.

3. Ghimire S, Nepal S, Bhandari S, Nepal P, Palaian S. A prospective surveillance of drug prescribing and dispensing in a teaching hospital in western Nepal. J Pak Med Assoc 2009; 59: 726-731.

4. Blum NL. Drug information development. A case study Nepal. Rational pharmaceutical management project. United States Pharmacopoeia 2000.

5. Singh G, Traidafilopulos G. Epidemiology of NSAIDs induced gastrointestinal complications. J Rheumatol 1999; 26: 18-24.

6. Singh G. Gastrointestinal complications of prescription and over-the-counter nonsteroidal anti-inflammatory drugs: a view from the ARAMIS data base. Arthritis, rheumatism, and aging medical information system. Am J Ther 2000; 7: 115-121.

7. Chan FK, Graham DY. Prevention of non-steroidal antiinflammatory drug gastrointestinal complications-review and recommendations based on risk assessment. Aliment Pharmacol Ther 2004; 19): 1051-1061.

8. Targownik LE, Thomson PA. Gastroprotective strategies among NSAID users: Guidelines for appropriate use in chronic illness. Can Fam Physician 2006; 52: 1100-1005.
9. Singh KUS, Pandey RC. Evaluation of prescribing pattern of doctors for rational drug therapy. Ind $\mathrm{J}$ Pharmacol 1998; $30:$ 40-46.

10. Uppal R, Nayak P, Sharma PL. Prescribing trends in internal medicine. Int $\mathrm{J}$ Clin Pharmacol Ther Toxicol 1984; 22: 375-376.

11. Pradhan SC, Shewade DG, Shashindran CH, Bapna JS. Drug utilization studies. Natl Med J India 1988; 1: 185-189.

12. Syed IS, Mohamed A, Jayadevan S, Kishore GS. Prescribing patterns in the Orthopedics outpatient department in GMC Hospital, Ajman, United Arab Emirate. Proceedings of the 6th Annual Scientific Meeting of Gulf Medical University 2014.

13. Shankar PR, Pai R, Dubey AK, Upadhyay DK. Prescribing patterns in the orthopaedics outpatient department in a teaching hospital in Pokhara, Western Nepal. Kathmandu Univ Med J 2007; 5: 16-21.

14. Das BP, Adhikari N, Garg M, Rauniar GP, Naga Rani MA. Utilization pattern of Nonsteroidal anti-inflammatory drugs (NSAIDs) in orthopaedic practice at a tertiary care hospital in eastern Nepal. J Nep Med Assoc 2000; 39: 315-318.

15. Fosbol E, Gislason G, Jacobsen S, Abildstrom S, Hansen M, Schramm T, Folke F Sørensen R, Rasmussen J, Kober L, Madsen M, Torp-Pedersen C. The pattern of use of non-steroidal anti-inflammatory drugs (NSAIDs) from 1997 to 2005: a nationwide study on 4.6 million people. Pharmacoepidemiol Drug Safety 2008; 17: 822-833.

16. IMS health IMS MIDAS quantum based on selected markets (ATC $=$ M1C oral solid forms only US\$ Actual growth in US\$ CER Q4 2008.

17. Graham D, Campen D, Hui R, Spence M, Cheetam C, Levy G, Shoor S, Ray W. Risk of acute myocardial infarction and sudden cardiac death in patients treated with cyclo-oxygenase-selective and non-selective nonsteroidal anti-inflammatory drugs: nested case-control study. Lancet 2005; 365: 475-481.

18. Johnsen S, Larsson H, Taone R. Risk of hospitalization for myocardial infarction among users of rofecoxib, celecoxib and another NSAIDs. Arc Int Med 2005; 165: 978-984.

19. Andersohn F, Suissa S, Garbe E. Use of first-and secondgeneration cyclooxygenase-2-selective nonsteroidal antiinflammatory drugs and risk of acute myocardial infarction. Circulation 2006; 113: 1950-1957.

20. Tandon V. VR pain killers and cardiovascular toxicity. Health Line Fam Med J 2006; 4: 33-34.

21. Trelle S, Reichenbach S, Wandel S, Hildebrand $\mathrm{P}$, Tschannen B, Villiger PM, Egger M, Jüni $P$. Cardiovascular safety of non-steroidal anti-inflammatory drugs: network meta-analysis. BMJ 2011; 342: 7086.

22. Jose V, Antonyn T. Recent trends in the utilization of NSAIDs in a tertiary care Hospital. Ind J Pharmacol 2003; 35: 318. 
23. Tiwari H, Kumar A, Kulkarni S. Prescription monitoring of antihypertensive drug utilisation at the Panjab University Health Centre in India. Singapore Med J 2004; 45: 117-120.

24. Kholoud ZQ, Ikbal NT, Nebal AA, Neris MH. Prescribing patterns of non-steroidal anti-inflammatory drugs in outpatient clinics at Royal Rehabilitation Center in King Hussein Medical Center. Zagazig Univ Med J 2014; 20 : 673-679.

25. Zandman-Goddard G, Langville P. The lack of awareness of the Israeli population regarding gastrointestinal complications from nonsteroidal anti-inflammatory drugs. Harefuah 2001; 140: 476-478.

26. Thompson PW, Tee L, McBride J, Quincey D, Strat Liddiard G. Long-term NSAID use in primary care: changes over a decade and NICE risk factors for gastrointestinal adverse events. Rheumatology (Oxford) 2005; 44: 1308-1310.

27. Taruna S, Dutta S, Dhasmana DC. Prescribing pattern of NSAIDs in orthopaedic OPD of a tertiary care teaching hospital in Uttaranchal. JK Sci 2006; 8.

28. Day R, Morrison B, Luza A. A randomized trial of the efficacy and tolerability of the COX-2 inhibitor rofecoxib vs. ibuprofen. Zagazig Univ Med J 2014; 20.

29. Saag K, Van der Heijde D, Fisher C . Rofecoxib, a new cyclooxygenase 2 inhibitor, shows sustained efficacy, comparable with other nonsteroidal anti-inflammatory drugs: a 6-week and a 1-year trial in patients with osteoarthritis. Arch Fam Med 2000; 9: 1124-1134.

30. Heyneman CA, Lawless-Liday C, Wall GC. Oral versus topical NSAIDs in rheumatic diseases: a comparison. Drugs 2000; 60: 555-574.

31. Isah AO, Ross-Degnan D, Quick J. The development of standard values for the WHO drug use prescribing indicators. WHO 2018.

32. Sarkar C, Das B. Prescribing trends in a teaching hospital in Western Nepal. J Nepal Med Assoc 2002; 2: 4-7.

33. Ravi Shankar P, Partha P, Nagesh S. Prescribing patterns in medical outpatients. Int J Clin Pract 2002; 56: 549-551.

34. Das N, Khan AN, Badini ZA, Baloch H, Parkash J. Prescribing practices of consultants at Karachi, Pakistan. J Pak Med Assoc 2001; 51: 74-77.

35. Shamsur R. Prescribing pattern of nonsteroidal antiinflammatory drugs at outpatient departments of teaching hospitals. Bangladesh J Pharmacol 2007; 2: 1-6.
36. Okezie Enwere O, Catherine OF, Babatunde LS. Drug prescribing pattern at the medical outpatient clinic of a tertiary hospital in Southwestern Nigeria. Pharmacoepidemiol Drug Safety 2007; 16: 1244-1249.

37. Erah PO, Olumide GO, Okhamafe AO. Prescribing practices in two health care facilities in Warri; southern Nigeria: a comparative study. Trop J Pharm Res 2003; 2: 175-185.

38. Isah AO, Ohaju-Obodo J, Isah EC, Ozemoya O. Drug use profile in a Nigerian city hospital. Pharmacoepidemiol Drug Saf 1997; 6: 319-324.

39. Ministry of Health Zimbabwe Essential Drugs Action Program. Essential Drugs Survey 1991.

40. Arebu IB, Ebrahim DO, Anwar M. Assessment of medicines use pattern using World Health Organizations prescribing, patient care and health facility indicators in selected health facilities in Eastern Ethiopia. BMC Health Serv Res 2016; 16: 144.

41. Desalegn AA. Assessment of drug use pattern using WHO prescribing indicators at Hawassa University Teaching and Referral Hospital, south Ethiopia: a crosssectional study. BMC Health Serv Res 2013; 13: 170.

42. Chanchal KD, Ajay K, Santanu B. Pattern of drugs use in orthopaedic outpatient department in a tertiary care teaching hospital in West Bengal. Ind J Bas Appl Med Res 2017; 7: 238-243.

43. WHO: How to investigate drug use in health facilities: selected drug use indicators. Geneva: WHO/DAP/93.1 1993.

44. Isenalumhe AE, Oviawe O. Polypharmacy: its cost burden and barrier to medical care in a drug-oriented health care system. Int J Health Serv 1988; 18: 335-342.

45. Ravi Shankar P, Partha P, Nagesh S. Prescribing patterns in medical outpatients. Int J Clin Pract 2002; 56: 549-551.

\section{*Correspondence to}

Mansour A. Mahmoud

Clinical and Hospital Pharmacy Department

College of Pharmacy

Taibah University

Saudi Arabia 